\title{
Analisa Strategi Bersaing Bisnis Bagi Orang Tua Murid TK Al-Ikhlas \\ Kabupaten Lumajang Tahun 2016
}

\author{
Noer Aisyah Barlian, S.KM,MM \\ STIE Widya Gama Lumajang \\ berlian.0302@gmail.com
}

\begin{abstract}
ABSTRAK
Penelitian ini bertujuan untuk meningkatkan jumlah pelaku bisnis disegala bidang usaha di Kabupaten Lumajang yang menuntut masyarakat memiliki keunggulan kompetitif dan berdaya saing. Ada beberapa langkah yang ditempuh pada pengabdian ini yaitu untuk menjawab permasalahan orang tua murid TK AL-IKHLAS sebagai berikut: (1) Dengan memahami dan mengetahui manfaat dalam menetapkan strategi dalam berbisnis dimasyarakat. (2) mendefinisikan bisnis yang telah ditekuni sekarang ini, (3) menganalisis kekuatan dan kelemahan yang ada dalam faktor internal bisnis yang dimiliki dan (4) menganalisis peluang dan ancaman yang ada dalam faktor eksternal bisnis yang dimiliki. Target pengabdian ini yaitu; (1) Peningkatan kemampuan menganalisis peluang dan mengembangan bisnis,(2) Mampu mempertahankan kelangsungan bisnis.
\end{abstract}

\section{Kata Kunci: Bisnis, Orang Tua, Strategi}

\section{ABSTRACT}

This study aims to increase the number of business people in all business sectors in Lumajang Regency who demand that the community has a competitive and competitive advantage. There are several steps taken in this service, namely to answer the problems of parents of students of AL-IKHLAS kindergarten as follows: (1) By understanding and knowing the benefits of setting a strategy in doing business in the community. (2) defining the business that has been pursued today, (3) analyzing existing strengths and weaknesses in the internal business factors and (4) analyzing the opportunities and threats that exist in the external factors of the business. The target of this service is; (1) Increased ability to analyze opportunities and develop business, (2) Able to maintain business continuity.

Keyword: Bussines, Parent, Strategic

\section{PENDAHULUAN}

\section{A. ANALISIS SITUASI}

Strategi bersaing merupakan sebuah langkah untuk menjadikan sebuah keunggulan kompetitif. Selain unggul juga mampu berdaya saing dalam jangka waktu yang lama atau berkelanjutan. Mengingat Kabupaten Lumajang telah dibanjiri dengan bisnis kuliner, tekstil, jasa dan lain-lain. Pelaku bisnis ini adalah dari kalangan mana saja, baik itu dari remaja sekolah, ibu-ibu rumah tangga dan bapak-bapak. Hal ini sangat baik untuk kemajuan perekonomian di Kabupaten Lumajang.

Perkembangan ekspedisi dan jasa antar barang yang semakin marak di Kabupaten Lumajang, membuat para pelaku bisnis baik offline dan online menjadi mudah dan cepat. Sehingga pelaku usaha binis baik itu kuliner, jasa dan perdagangan menjadi meningkat. Maka 
untuk dapat bersaing dalam persaingan pasar yang ketat harus memiliki strategi bersaing yang cocok agar dapat memberikan keunggulan kompetitif yang berkelanjutan.

Kelompok sasaran dalam kegiatan ini yaitu ibu-ibu dan bapak yang menjadi orang tua murid di TK AL-IKHAS. Hal ini mengingat di lingkup kecil kelompok ibu-ibu telah menjalankan proses kegiatan ekonomi dengan proses perdagangan yaitu jual beli barang. Selain itu terdapat banyak pengusaha sukses dalam bidang kuliner yang ditekuni oleh orang tua murid TK AL-IKHLAS.

\section{B. PERMASALAHAN}

Berdasarkan penjelasan tersebut yang melatarbelakangi dilaksanakannya pengabdian masyarakat yaitu meningkatnya jumlah pelaksana bisnis disegala bidang usaha di Kabupaten Lumajang yang mengharuskan masyarakat memiliki keunggulan kompetitif dan berdaya saing.

\section{SOLUSI DAN TARGET LUARAN}

\section{A. TARGET KEGIATAN}

Kegiatan pengabdian kepada masyarakat ini diharapkan dapat menghasilkan target sesuai, sebagai berikut:

1. Peningkatan kemampuan menganalisis peluang dan mengembangan binis.

2. Mampu mempertahankan kelangsungan bisnis.

\section{B. LUARAN KEGIATAN}

Kegiatan Pengabdian Masyarakat ini di harapkan memberikan luaran bagi mitra sebagai berikut :

1. Perluasan pasar didalam daerah

2. Pendampingan strategi pemasaran

\section{METODE PELAKSANAAN}

\section{A. TAHAPAN DALAM MELAKSANAKAN SOLUSI}

Beberapa langkah yang ditetapkan dalam kegiatan pengabdian ini untuk menjawab permasalahan orang tua murid TK AL-IKHLAS sebagai berikut:

1. Langkah pertama, dengan memahami dan mengetahui manfaat dalam menetapkan strategi dalam berbisnis dimasyarakat.

2. Langkah kedua, medefinisikan bisnis yang telah ditekuni sekarang ini, 
3. Langkah ketiga, menganalisis kekuatan dan kelemahan yang ada dalam faktor internal bisnis yang dimiliki.

4. Langkah keempat, menganalisis peluang dan ancaman yang ada dalam faktor eksternal bisnis yang dimiliki.

\section{B. METODE PENDEKATAN YANG DITAWARKAN}

Metode pendekatan yang ditawarkan untuk menyelesaikan permasalahan terdiri dari langkah-langkah sebagai berikut :

1. Wawancara

Pelaksanaan wawancara bertujuan untuk menggali informasi terkait permasalahan permasalahan pelaku usaha dan sekaligus menemukan solusinya.

2. Analisis

Menganalisis kekuatan dan kelemahan yang ada pada permasalahan pelaku usaha.

3. Solusi

Menerapkan solusi yang diambil dan saran-saran marketing

4. $\quad$ Monitoring dan evaluasi

Kegiatan monitoring dan evaluasi akan dilaksanakan secara periodik sampai mitra dapat menghasilkan produk-produk yang inovatif sehingga target dan luaran program ini bisa tercapai.

\section{HASIL YANG DI CAPAI}

\section{A. WAWANCARA}

Persiapan awal untuk memahami sebuah strategi bisnis yaitu dengan melakukan wawancara kepada pelaku bisnis. Pelaku usaha atau orang tua wali murid menceritakan permasalahan bisnis yang sedang dialami. Menceritakan berbagai pengalaman yang pernah terjadi di kegiatan bisnis internal dari saat membuka usaha sampai kondisi sekarang. Kemudian pelaku usaha dalam hal ini orang tua wali murid TK Al-Ikhlas diminta untuk menjelaskan lebih detail permasalahan yangsedang dialami terutama pada hal-hal yang mengancam bisnis mereka. Pelaku usaha atau orang tua wali murid menjelaskan banyaknya usaha atau bisnis yang merambah didunia maya sehingga usaha atau bisnis mudah ditiru serta mudah mengambil pelanggan orang lain. Hubungan antar pelaku usaha menjadi semakin tidak baik sehingga hubungan bisnis menjadi tidak sehat. 


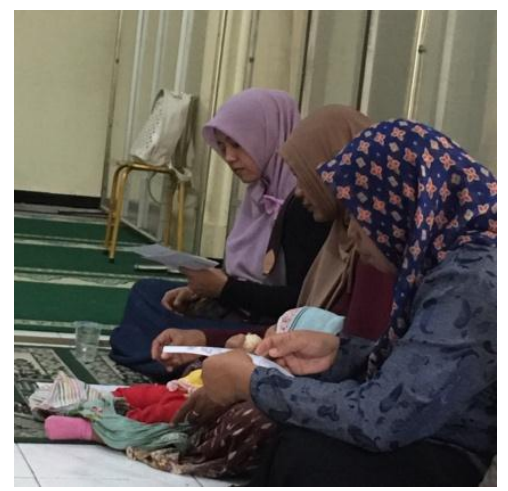

Gambar 1. Para Wali Murid TK Al-Ikhlas Memahami Materi Wawancara

\section{B. ANALISIS}

Setelah dilakukan wawancara mendalam dengan pelaku usaha atau orang tua wali murid, dilanjutkan dengan menjawab atau mendaftar kelemahan dan kekuatan bisnis yang dimilikinya. Bersama-sama dengan pelaku usaha membuat daftar analisis kekuatan dan kelemahan usaha atau bisnis yang sedang ditekuni dan saling memberikan pandangan dan saling menganalisis. Berlatih memberi bpbpt dari yang tertinggi sampai ke rendah pada daftar-daftar kelemahan dan kekuatan yang sedang dialami.

1. Kelemahan dalam perusahaan

2. Kekuatan dalam perusahaan

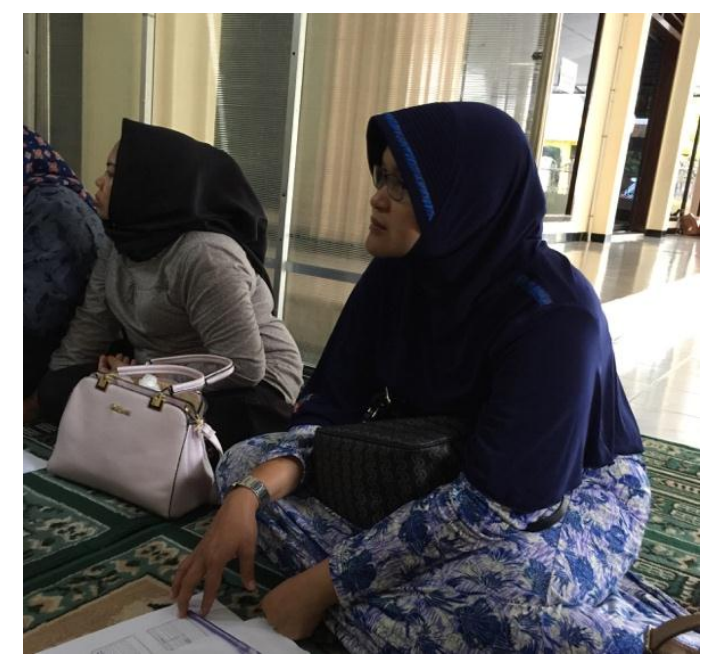

Gambar 2. Wali Murid Mendaftar Analisis Strategi Bisnis Yang Dimiliki

\section{SOLUSI}

Setelah membuat daftar kelemahan dan kekuatan pada bisnis orang tua atau wali murid TK Al-Ikhlas kemudian berdiskusi untuk mencari solusi yang dapat dilaksanakan dalam waktu dekat dan jangka panjang. Alat analisis untuk mendapatkan solusi dari permasalahan yang ada yaitu menggunakan analisis SWOT. Solusi yang dapat dilaksanakan dalam waktu dekat oleh pelaku usaha yaitu menjadi lebih pintah dan ahli dalam mempromosikan produk melalui sosial media. Menjadi lebih ahli dalam memberikan ciri 
khas pada karya-karya atau hasil olahan tanganya dengan menjadikan sebuah produk yang khas di Kabupaten Lumajang serta menjadi orang pertama yang meluncurkan produk tersebut sebelum orang lain. Lebih banyak menghindari hasil karya yang umum atau membuat produk yang serupa dengan produk ang telah beredar dipasaran.

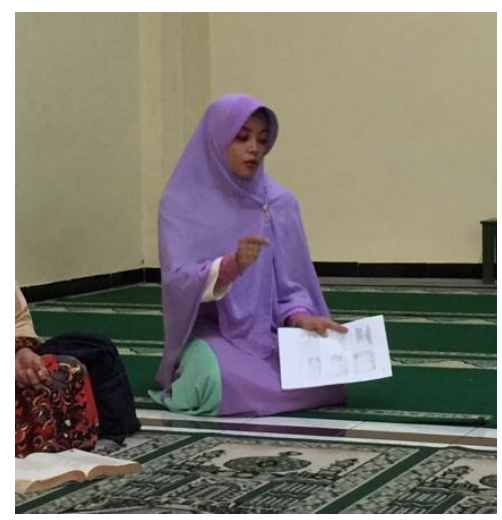

Gambar 3. Mencari Solusi Dari Permasalahan Bisnis

\section{MONITORING DAN EVALUASI}

Setelah mendapatkan solusi dari proses analisis kelemahan dan kekuatan perusahaan yang dipecahkan dengan menggunakan analisis SWOT maka langkah selanjutnya yaitu pelaksanaan solusisolusi sesuai dengan permasalahan bisnis masing-masing. Pelaksanaan solusi merupakan sebuah kemauan para pelaku usaha untuk terus melakukan pengembangan dan pembaharuan dalam berbagai segi baik internal dan eksternal agar dapat berdaya saing di lingkungan. Para pelaku usaha atau wali murid TK Al-Ikhlas dalam melaksanakan solusi yang dapat dilaksanakan dalam waktu dekat selama 2 bulan kemudian dilakukan monitoring kembali terhadap hasil-hasil pelaksanaan solusi tersebut.

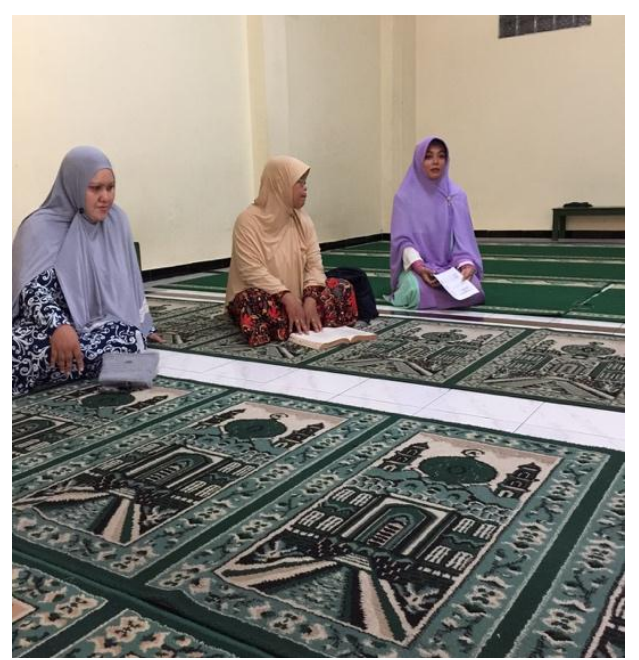

Gambar 4. Kesepakatan Untuk Melaksanakan dan Melakukan Monitoring dan Evaluasi Bertahap 


\section{PENUTUP}

\section{Kesimpulan}

Program pengabdian masyarakat ini dapat membuka wawasan masyarakat terutama ibu-ibu wali murid TK Al-Ikhlas yang memiliki bisnis dalam upaya untuk mempertahankan eksistensi didalam dunia bisnis. Para pelaku usaha memahami dan dapat mengimplementasikan cara untuk mendapatkan strategi terbaik dan tepat untuk bisnis yang ditekuni.

\section{Saran}

Berdasarkan kegiatan yang telah dilakukan maka dapat diajukan beberapa saran sebagai

berikut :

1. Adanya kegiatan sejenis hendaknya selalu diselenggarakan secara periodik sehingga dapat meningkatkan pengetahuan pelaku bisnis terutama ibu-ibu dalam mempertahankan bisnisnya

2. Dapat dengan mandiri menyelesaikan persoalan dalam bisnis 